\title{
Research on the Ethnic Minority English Teachers in Middle Schools' Perplexity of Professional Development and Its Solution*
}

\author{
Hui Shi \\ Institute of International Education, Jishou University, Hunan, China
}

\begin{abstract}
This study makes an empirical study on the professional development of ethnic minority English teachers in middle school. Four ethnic minority English teachers of different ages who volunteer to participate in qualitative interviews are selected to conduct the in-depth interviews to analyze their professional development. According to the analysis of research results, it is found that the main puzzles of ethnic minority English teachers' professional development are how to balance the gap between the content of teaching materials and the actual teaching situation; how to avoid the emergence of teaching tendency in teaching; how to realize the positive transfer of professional development in mother tongue cultural environment. Finally, the solutions are put forward to solve the confusion from the social level and personal level.
\end{abstract}

Index Terms - teacher professional development, the confusion of professional development, the solutions

\section{INTRODUCTION}

The modernization is developing rapidly nowadays, teachers are surrounded by uncertainty, their current behaviors are constantly subverted. As ethnic minority foreign language teachers, on the one hand, they have more opportunities to understand western culture and be influenced by globalization than other teachers; On the other hand, this kind of influence may conflicts with their personal practical knowledge, local habits and ethnic minority culture, which leads to the generation of anxiety in work. It is such conflicts and contradictions in practice that threaten the security of teachers, therefore, their experience need to be re-examined, evaluated and reconstructed. Research on ethnic minority foreign language teachers' professional development confusion, can stimulate their cultural consciousness, understand their internal psychological mechanism well, and promote the basic education of foreign language in ethnic areas.

\section{RESEARCH DESIGN AND DATA PRESENTATION}

First, the study selects four ethnic minority English teachers of different ages who are willing to conduct qualitative research, the ways of reflection diary, classroom observation as well as in-depth interviews are used to analyze the confusion of their professional development. Second, all the data are transformed into text data, and presented in the form of text. Finally, the analysis results are verified by the way of verification triangle. The four interviews' questions of qualitative interview and the content of foreign language teachers' professional development in the study are mainly based on the definition of foreign language teachers' professional development by Jia (2005), Wu (2008), Freeman (1989), Richards \& Nunan (1990), Peirce (1995), Hall (1995), Johnson (2006), Benesch (2012), Aneja (2016). It is believed that the professional development of foreign language teachers is driven by teachers' inner self-development consciousness, they improve professional feelings, professional knowledge and professional skills by continuous learning, reflection and growth. Combine with the scholars' definition of foreign language teachers' professional development above, the content of teachers' professional development involves professional ability, teachers' knowledge, teachers' belief, professional ethics as well as self-development and so on, which emphasizes teachers' psychological change process in the accumulation of knowledge, the improvement of professional technology and the transformation of emotional state. The followings are some of the core interview data:

\section{A. What Do You Think of Your Duty in Your Work?}

The question mainly investigates teachers' professional values and professional development attitudes. The answers of the four teachers are summarized as follows:

I think my profession is to preach, teach and solve doubts, help my students understand more English knowledge and make them interested in English learning. (Miss Long)

My job is to train more excellent students. Our students have a poor knowledge in English. Some of them can't even write down 26 letters. It's unrealistic to pass the college entrance examination. So my duty is to help my students get

\footnotetext{
${ }^{*}$ This research is one of the results of the 2019 Project of the $13^{\text {th }}$ Five-Year Plan of Education Science in Hunan Province, which is "Research on the Ethnic Minority English Teachers in Middle Schools' Perplexity of Professional Development and Its Solution” (No. Xjk19qmz001).
} 
high marks in the college entrance examination. (Miss Shi)

My job is to educate students, and cultivate talents for my hometown. No matter how my ability is, I should do my job well and have a sense of responsibility in post. (Miss. Hong)

It is my pride and duty to cultivate excellent talents for the nation and society. We can't use English to teach English, but give full play to the advantages of English to carry forward the traditional culture of our nation, which make more people in the world care about and understand our minority nationality. It is the responsibility of my teaching English. (Mr. Liang)

The six moral norms put forward in The Code of Professional Ethics for Primary and Secondary School Teachers (revised in 2008): Patriotism and law-abiding, teaching and educating, being a teacher, loving and dedicated to their posts, caring for students, and lifelong learning are the evaluation standard of teachers' profession. It can be seen from the above data that Miss long believes that her duty is to transfer professional knowledge to students, which reflects the norms of teaching and educating people; Miss Shi believes that her duty is to help students improve their performance and scores, which also reflects the norms of teaching and educating people; Miss Hong believes that her duty is to fulfill his duty in her post, which reflects the norms of love and dedication; and Mr. Liang believes that his duty is to cultivate excellent students and carry forward national culture, which reflects the norms of teacher education, patriotism and law-abiding and lifelong learning. It can be seen that four teachers are responsible for teaching, and have a positive sense of professional responsibility and teaching attitude.

\section{B. What Do You Think of the English Textbooks Using Currently?}

The question mainly investigates the ethnic minority teachers' views on using teaching materials currently. The four teachers' answers are summarized as follows:

We are now using the Go for It from People's Education Edition. I think the textbook has nothing to do with our examination, and it is difficult to adapt to the need of our Miao children. Many teachers complain that the formal examination content is too different from the teaching materials. (Miss Long)

The high school textbook what we are using now is from People's Education Edition. The overall feeling is very good, but the drawback is that there is no information and vocabulary about ethnic minorities. Furthermore, if the textbook can set up a special section for oral practice, teachers will cultivate students' communicative ability consciously, rather than written test ability currently. (Miss Shi)

The high school textbook what we are using now is from People's Education Edition. Eighty percent of my students are Miao, their basic English knowledge is very poor. The total score of 150 points in the middle school entrance examination, most of them just get 20 or 30 points. So my teaching goal is to succeed as long as students can get 50 points in the college entrance examination. Meanwhile, we mainly focus on the words and grammar in teaching. (Miss Hong)

We are now using the Go for It from People's Education Edition. The pictures and colors of the teaching materials are well designed, which can stimulate student's interest in learning. There are many teaching materials, words and reading contents in the unit of textbook, but lack of local vocabulary, for instance, "Hamburga", a food we haven't eaten and seen before, so it is hard to teach without in a real situation. (Mr. Liang)

Through the analysis of qualitative data above, it is known that the two junior middle school teachers use the English experimental textbook Go for It, and the two senior high school English teachers use The Ordinary High School Curriculum Standard Experimental Textbook from People's Education Version. Miss Long believes that there is a big difference between the teaching material and the actual examination. Therefore, she is confused about how to deal with the gap between the teaching content and the actual examination. Mr. Liang believes that the picture design of the textbook is well designed, but involves a lot of reading content and lacks local vocabulary, which is not suitable for the actual situation of his students, he thinks there is a big gap between the content of the textbook and the actual examination goal. Miss Shi is confused about what teaching strategies to choose to balance students' communicative ability and written ability, she believes that the textbooks lack minority cultural vocabulary and oral section. Miss Hong believes that the textbook is not suitable for the actual level of her students, but she actively changes the educational concept and flexibly uses the textbook in combination with the actual need of students. It can be seen that the four teachers have different puzzles and opinions on their current teaching materials.

\section{Is There Any Teaching Tendency in Your Teaching?}

Teaching tendency refers to that some foreign language teachers tend to teach a certain knowledge in the process of teaching, such as excessively preferring to the teaching of oral or pronunciation, while ignoring the teaching of grammar, writing and other knowledge (Shi \& Jiang, 2017, p.73). The question mainly investigates that whether teachers appear teaching tendency in their teaching process or not. The responses of the four teachers are summarized as follows:

In the process of my teaching, I mainly tend to improve students' listening and speaking ability. I will arrange many strategies in class, such as companion reading, group reading, recitation and reading aloud so as to improve students' listening and speaking ability. There are no learning opportunities in our group on account of only five English teachers in our school, so I don't know whether other teachers do like this or not. (Miss Long)

I have paid more attention to the use of syntax since I taught, such as how to express sentences in English. Some of 
my colleagues pay attention to grammar, and some to write. Because reading comprehension can get high marks in the examination. (Miss Shi)

I mainly focus on reading and writing in teaching. If I do a good job in reading and writing, I can complete the regulations of our school, that is, the student's paper score reaches 60 points. I mainly teach students some reading skills, such as the skills of how to improve vocabulary. Furthermore, I have done the paper of the college entrance examination to master the skills of examination in order to improve student's test scores. (Miss Hong)

I don't like teaching reading; I think reading is too boring, so do the students. I try my best to make the reading class active and efficient. But I don't know how to attract students' attention. (Mr. Liang)

It can be seen from the above data that Miss long tends to practice language knowledge and use memory strategies, while ignore the structural system. Such as she only pays attention to the cultivation of students' listening and speaking ability in her teaching, and doesn't know how to improve teaching strategies or update personal teaching experience. In addition, Miss Shi and Miss Hong tend to practice language's structure while ignore language's function and meaning intentionally or unintentionally, for instance, Miss Shi tends to teach reading and syntax while ignore the teaching of oral and listening consciously; Miss Hong tends to teach reading and writing, and summarize teaching knowledge by doing college entrance examination questions; Mr. Liang ignores the learning of language knowledge structure system intentionally. Obviously, the four teachers appear teaching tendencies in their teaching practice implicitly or explicitly. The emergence of teaching tendency is not conducive to teachers' professional development.

\section{What Kind of Confusion Have You Ever Encountered in the Process of Your Professional Development?}

This question mainly investigates the types of confusion in teachers' professional development. The responses of the four teachers are summarized as follows:

First, there is no English learning atmosphere in our ethnic areas, so how can I improve my students' interest in learning English is my first puzzle. Second, the examination is too far from the syllabus, the contents and essays in the textbook are very long, but the actual examination is very simple. How can I find the appropriate teaching method in this situation is my second puzzle. (Mr. Long)

My confusion is how to balance the relationship between students' communicative competence and test competence. Since the new curriculum standard requires to cultivate students' communicative competence, why not set up an oral test in the college entrance examination? If the oral test is set, the teacher will cultivate students' communicative ability in the usual teaching consciously, rather than written test ability currently. (Miss Shi)

My biggest confusion now is that I haven't formed my own teaching model since I was a teacher. I have been trying to explore and change my teaching mode. However, my students may be affected by my exploration. (Miss Hong)

My confusion is how to deal with the relationship with student's parents in my cultural environment. For example, after a teacher in our school dragged a naughty child into the office, the whole village people rushed into the teacher office and beat that teacher. So I dare not discipline students. Another time when we visited Miao village, I forgot that the innermost side of the fire pit was the position of their ancestors. I directly moved a bench to sit there. As a result, parents of that family kicked me out. (Mr. Liang)

The professional development of foreign language teachers in minority areas is influenced by ethnic minority culture, personal practical knowledge and other factors. Influenced by factors such as region, teaching situation as well as personal teaching experience, Miss long does not know how to stimulate students' interest in learning English, and how to balance the gap between textbook content and examination level. Miss Shi works in the key ethnic middle school of the county, influenced by personal practical knowledge as well as other factors, her confusion is how to balance the relationship between students' communicative competence and written examination competence. Due to the influence of personal practical knowledge, Miss Hong is confused about how to form her own teaching strategies in teaching practice without hindering the development of her students. Mr. Liang is teaching in Miao area, influenced by the local ethnic customs and teaching atmosphere, his confusion is how to deal with the relationship with students' parents well in the ethnic cultural environment.

\section{ANALYSIS OF RESEARCH RESUltS}

Through the analysis of qualitative data above, ethnic minority English teachers in middle school mainly carry out their professional development by self-reflection, teaching innovation and taking themselves as resources and so on. However, there are mainly the following puzzles in the process of their professional development:

\section{A. How to Balance the Gap between the Content of Teaching Materials and the Actual Teaching Situation}

English Curriculum Standards requires that the setting and teaching of English curriculum should be conducive to the development of students' personality and potential, to cultivate students' emotional attitude, cultural awareness, language knowledge and learning strategies, so as to promote students' comprehensive language application ability and comprehensive humanistic quality. Ethnic minority teachers will face complex conflicts of language culture and real situation on account of the limitations of working environment, cultural environment and personal practical knowledge. Therefore, some teachers take the teacher-centered teaching model to evaluate students' learning English in the process of implementing textbook design and teaching, which violates the norms and original intention of teaching materials in 
reality. For instance, Miss Hong only pays attention to the explanation of words and grammar in teaching to improve students' score in examinations. Although teachers realize that pay too much attention to the written test ability will restrict students' development, but they often forget their internal voice and to shape themselves into a model in line with the actual situation. In addition, Mr. Liang and Miss Shi are confused about how to deal with the gap between the content of the textbook and the actual examination level, and the confusion of Miss Shi is how to exercise students' oral ability based on the teaching materials. Obviously, how to balance the gap between the content of teaching materials and the actual teaching situation to promote students' comprehensive language application ability, is the mainly puzzle faced by ethnic minority English teachers in middle schools.

\section{B. How to Avoid the Emergence of Teaching Tendency in Teaching}

Teaching tendency refers to that some foreign language teachers tend to teach certain knowledge in the process of teaching, such as excessively preferring to the teaching of oral or pronunciation, while ignoring the teaching of grammar, writing and other knowledge. Such as Miss long pays attention to improve students' listening and speaking by creates communication opportunities for students while ignore the teaching of grammar; Mr. Liang avoids the implementation of reading teaching strategies consciously in class; Miss Shi and Miss Hong focus on reading, grammar and word knowledge during teaching in order to improve students' performance. It is not difficult to see that the teaching tendency appears in four teachers' teaching implicitly or explicitly, some of them overemphasize the importance of teachers' imparting knowledge while ignore students' own learning experience; some overemphasize language structure knowledge' learning while ignore learners' actual communicative ability; and some overemphasize language' meaning while ignore the knowledge of language structure. Many activities are designed to consolidate language knowledge while ignore language' meaning and function by teachers intentionally or unintentionally in classroom. The emergence of teaching tendency is not conducive to teachers' professional development. Therefore, how to avoid teaching tendency in teaching practice is one of the puzzles of ethnic minority foreign language teachers.

\section{How to Realize the Positive Transfer of Professional Development in Mother Tongue Cultural Environment.}

Lado (1957) believes that learners can transfer the form and meaning of their mother tongue language to the foreign language that they have learned, transfer can be divided into positive transfer and negative transfer, positive transfer refers to the mother tongue' behavior, rules and culture can promote the learner's second language acquisition, and vice versa. Ethnic minority foreign teachers can appear contradictions and confusions in their teaching practice on account of conflicts in different cultures and rules. Such as Miss Long can't pronounces some English phonetics due to the influence of her mother tongue, which resulting in negative transfer in her second language learning, but positive transfer appears in her Japanese learning, similarly, Mr. Liang also appears the negative transfer in his professional development. The negative transfer make teachers' professional knowledge is challenged and threatened continuously, and job burnout will be appeared in work. Therefore, how to realize the positive transfer of professional development in mother tongue culture is one of the main puzzles faced by ethnic minority English teachers.

\section{WAys to Resolve the Confusion of Teacher’s PRofessional DeVElopMent}

\section{A. To Carry out Foreign Language Teacher Training and Teacher Education Policies in Ethnic Minority Areas}

We should consider ethnic minority foreign language teachers' commonness and individuality when formulating the education training, and strengthen the teaching concept for them from the aspects of linguistics, psychology and subject knowledge. We can adopt a transitional way to narrow the gap between policy requirements and teachers' adaptability, such as basic training before implementation, modification during implementation, and effect evaluation after implementation. Educational trainers can implement situational training modes, such as participatory training or "shadow" training so that teachers are able to continuously, comprehensively as well as carefully observe the excellent teachers' teaching cases, they can actively participating in practical teaching activities by the collective lesson preparation, group discussion, classroom observation and so on. In addition, practice community can be established by group cooperation, teacher apprentice cooperation as well as international exchange and so on, to improve teachers' professional skills. The school authority is able to provide teachers with the opportunities of observing national excellent English teacher competitions to promote their competence, participating in backbone teacher training to enhance their individual self-confidence, and supporting excellent teachers to go abroad for further study.

\section{B. To Give Teachers More Rights and Create a "People-Oriented" Working Atmosphere}

Ethnic minority foreign language teachers face diverse cultural conflicts on the implementation of foreign language education in ethnic minority areas. Therefore, the school authority needs consider teachers' emotion and inner world when formulating relevant policies and evaluation mechanisms, the school authority should give teachers more professional autonomy, professional development rights, decision-making rights and independent innovation rights to enhance teachers' confidence and professional identity, for instance, teachers can participate in school curriculum reform and formulate semester teaching plans. In addition, school authority should create a "people-oriented" working atmosphere to solve teachers' practical problems, care about teachers' family and work, make teachers feel the warmth of the collective and increase their sense of collective identity; the school authority should pays attention to the habits or 
beliefs of teachers in different ethnic minorities and cultures, organize the activities to enhance the cohesion of the group, encourage and respect teachers to improve their teaching confidence.

\section{Ethnic Minority Foreign Language Teachers Should Have the Consciousness of Critical Reflection in Practice.}

Ethnic minority foreign language teachers need reflect on themselves based on individual experience both inside and outside, learn to reconsider their past experience and integrate it with the current experience in daily teaching, so as to better face the challenges in the future. Teachers need learn to reflect on self-existence and realize the significance of self-existence, for example, when face the confusion that how to balance the gap between the content of teaching materials and the actual teaching situation, teachers can constantly explore and develop themselves in reflection to strengthen their self-concept. Teachers can promote professional development by teaching reflection, such as self-reflection, pair reflection and group reflection. Teaching reflection urges teachers construct and integrate their classroom behavior continuously to obtain new understanding in teaching, teachers can construct individuality in reflection and development in reflection. At the same time, the teachers' self-development consciousness is an important internal cause to reduce job burnout and identity crisis, therefore, minority foreign language teachers need improve their self-development awareness, because those who pursue self-development and self-realization do not feel any anxiety. The reflective behaviors of teachers are a primary factor affecting teaching ability and professional knowledge. Teachers can reconstruct their understanding of work by positive response to the working environment.

\section{CONCLusion}

This study makes an empirical study on the professional development of ethnic minority English teachers in middle school. Four ethnic minority English teachers of different ages who volunteer to participate in qualitative interviews are selected to conduct the in-depth interviews to analyze their professional development. The results show that the main puzzles of ethnic minority English teachers' professional development are how to balance the gap between the content of teaching materials and the actual teaching situation; how to avoid the formation of teaching tendency in teaching; how to realize the positive transfer of professional development in mother tongue cultural environment. Finally, the solutions to solve the confusion are put forward that to carry out foreign language teacher training and teacher education policies in ethnic minority areas; to give teachers more rights and create a "people-oriented" working atmosphere; ethnic minority foreign language teachers should have consciousness of critical reflection in practice. Due to the limited space, the deficiency of study is that it cannot present the data of quantitative research in detail. The follow-up researches can pay attention to the influence ways of their professional development.

\section{REFERENCES}

[1] Aneja, G. A. (2016). (Non)native Speakered: Rethinking (Non)nativeness and teacher identity in TESOL teacher education. TESOL Quarterly, (3), 572-569.

[2] Benesch, S. (2012). Considering Emotions in Critical English language Teaching: Theories and Praxis. New York: Routledge Press.

[3] Freeman, D. (1989). Teacher training, development, and decision-making: a model of teaching and related strategies for teacher education. TESOL Quarterly, 23(1), 27-46.

[4] Hall, J. K. (1995). (Re)creating our worlds with words: A sociohistorical perspective of face-to-face interaction. Applied Linguistics, (16), 206-232.

[5] Jia Aiwu. (2005). Professional status and professional development connotation of foreign language teachers. Foreign languages and foreign language teaching, (4), 57-59.

[6] Johnson, K. E. (2006). The social-cultural turn and its challenges for second language teacher education. TESOL Quarterly, 31(4), 681-712.

[7] Lado, R. (1957). Linguistics Across Cultures Applied Linguistics for Language Teachers. Ann Arbor University of Michigan Press.

[8] Peirce, B. N. (1995). Social identity, investment, and language learning. TESOL Quarterly, (29), 9-31.

[9] Richards, J. C. \& Nunan, D. (Eds.). (1990). Second Language Teacher Education. Cambridge University Press.

[10] Shi Hui, \& Jiang Yuhong. (2017). A study on foreign language teachers' teaching tendency -- Based on Teachers' personal practical knowledge. Journal of Teacher Education, (3), 73-79.

[11] $\mathrm{Wu}$ Yi an. (2008). Research on the education and development of College English teachers in China. Beijing foreign language teaching and Research Press.

Hui Shi was born in Hunan Province, China in 1985. She received her doctoral degrees in foreign linguistics and applied linguistics from Southwest University, China in 2019. She is currently a lecturer in the Institute of International Education, Jishou University, Hunan, China. Her research interests include second language teacher education and applied linguistics. 